\title{
Professionalism and its role in the formation of medical professional identity
}

\author{
Mina Forouzadeh ${ }^{1}$, Mehrzad Kiani², Shabnam Bazmi*2 \\ Received: 3 Dec 2017 \\ Published: 26 Dec 2018
}

\begin{abstract}
Background: The honorable medical profession is on the verge of being reduced to a business. Evidence suggests that professionalism is fading and today's doctors are faced with value-threatening problems and gradually begin to forget their main commitment as medical professionals. Many of the problems faced by doctors are rooted in non-professionalism. Mere education in the science and practice of medicine produces an inefficient medical workforce and leads to the formation of a distorted professional identity. In the past decade, educational innovations targeting the formation of desirable professional identities have been presented and are considered a vital part of medical education for the development of professionalism. The present study was conducted to examine the relationship between the formation of professional identity and professionalism. Professionalism education is essential in the formation of a desirable professional identity.

Methods: This review article was done in 2015 through searching databases, such as PubMed, Elsevier, Google Scholar, Ovid, SID, and IranMedex, using keywords of professionalism and professional identity, and medical education. Among the 55 found articles, 30 were assessed and selected for review.

Results: The formation of professional identity is a process with the following domains: professionalism, and development of a personal (psychosocial) and a cultural identity, which is derived from the unification of professional, personal, and ethical development. The main components required for the formation of a desirable identity are, therefore, rooted in the dimensions of professionalism and professional development. The need for teaching professionalism has a reciprocal relationship with the formation of professional identity.

Conclusion: There is a reciprocal relationship between formation of a desirable professional identity and development and strengthening of professionalism. Modern medical education should be designed to develop professional identity, and professionalism acts as an essential part of its curricula throughout the entire course of a doctor's education, with the aim of acquiring a desirable professional identity.
\end{abstract}

Keywords: Professionalism, Professional identity, Medical education

\author{
Conflicts of Interest: None declared \\ Funding: None \\ *This work has been published under CC BY-NC-SA 1.0 license. \\ Copyright $\odot$ Iran University of Medical Sciences
}

Cite this article as: Forouzadeh M, Kiani M, Bazmi Sh. Professionalism and its role in the formation of medical professional identity. Med J Islam Repub Iran. 2018 (26 Dec);32:130. https://doi.org/10.14196/mjiri.32.130

\section{Introduction}

Since the late 1960s, the issue of ethical patient care, with origins in the Code of Hammurabi and the Hippocratic

Corresponding author:DrShabnam Bazmi, sh_bazmi2003@yahoo.com

\footnotetext{
1. Medical Ethics Department, Iran University of Medical Sciences, Tehran, Iran

2. Medical Ethics Department, School of Traditional Medicine, Shahid Beheshti University of Medical Sciences, Tehran, Iran
}

Oath, has been vehemently raised in the US. In 1999, the Accreditation Council for Graduate Medical Education

$\uparrow$ What is "already known" in this topic:

The necessity of professionalism in medicine and teaching it to learners.

\section{$\rightarrow$ What this article adds:}

The reciprocal relationship between establishing a desirable professional identity and developing professionalism and modern medical education should lead to a desirable professional identity, with professionalism as an essential part of its curricula. One of the key elements in the formation of a professional identity is the promotion of professionalism, and thus modern medical education should be designed in such a way to devote a significant part of the curriculum of student education to professionalism. 
(ACGME) took measures to reinforce and put the general capabilities of all specialized disciplines into practice. Accordingly, all the graduates of specialty and subspecialty medicine had to be able to demonstrate these crucial capabilities. Professionalism was one of these 6-fold capabilities. Clinical students needed to practice and demonstrate to this board their commitment to professional responsibilities, their adherence to the principles of medical ethics, and their sensitivity to different patient communities. The Association of American Medical Colleges (AAMC) confirms professionalism as a necessary element for being a good doctor. Stern argues that professionalism is founded on 3 components: clinical competence, communication skills, and ethical understanding (1). This definition emphasizes the fact that professionalism is a set of attitudes and conducts in medical students and doctors that includes 3 basic principles:

1. The prioritization and welfare of the patient: This principle is based on a commitment to the patients' interests, with philanthropy as a main component that strengthens the doctor-patient relationship.

2. Patient autonomy: Doctors should respect the patients' autonomy, be honest with them, empower them for making informed decisions about their treatment, and prioritize their decisions regarding their own care.

3. Social equity: The medical profession should promote equity in the health system, which involves the fair distribution of medical resources.

Doctors should actively seek to actualize the 3 principles of medical professionalism through adherence to the following 10 responsibilities to eliminate discrimination from the health system based on race, gender, economic status, ethnicity, religion, and social class:

1. Competence and ability to perform medical work and maintain, improve, and update these capabilities

2. Honesty with the patients

3. Patient confidentiality

4. Establish a good and proper relationship with the patients

5. Improve the quality of services provided to the patients and the community

6. Improve the community's access to medical care and help expand medical services and establish universal health care

7. The fair distribution of the limited medical resources available, including time and services

8. Maintain the community's trust

9. Scientific knowledge and commitment to learning: Ongoing professional medical education should not be restricted to medicine, and other sciences, especially human sciences, history, and philosophy, should also be learnt.

10. Professional accountability (2).

\section{Methods}

The research method was reviewed in this review article. By reviewing accessible articles electronically and using such keywords as professional identity and medical education, internet search was performed and existing literature and resources were studied. Based on the studies, professionalism and its principles were first defined. Then, the reasons for the need for professionalism and professional identity were investigated. Next, the process of forming a professional identity in a medical student was analyzed.

\section{The necessity of professionalism in medicine}

The honorable medical profession appears to be turning into a "pay for service" business, and this transformation is manifested in many developed and developing countries as a gradual loss of trust in doctors. Evidence suggests that professionalism is fading and today's doctors are faced with value-threatening problems and gradually begin to forget their main commitment as medical professionals (3). Many problems faced by doctors are rooted in non-professionalism (4). A review of literature on professionalism reveals that medical educators have come to emphasize this issue and are trying to overcome these threats. Changes, therefore, need to be made to the current medical culture, education environment, and curriculum as a step in the promotion of professionalism. Mere education in the science and practice of medicine produces an inefficient medical workforce that not only has less constructive results for the community and patients, but also puts people at risk (5). There has been much debate on the issue of professionalism in recent years and scholars have come to place a great emphasis on the importance of teaching professionalism in medical sciences universities, and this attribute is now considered a key aspect of medical education. Therefore, a doctor needs a strong professional identity, both in ethical and clinical aspects, to confidently practice medicine. Students who have acquired all the knowledge and practical skills required for their field will hardly be successful in the medical profession unless they develop a desirable professional identity (6).

Thus, the concept of professionalism is not the same as professional identity, as professional identity refers to how the individual perceives himself as a doctor, while professionalism refers to the possession and exhibition of the conduct of a professional. The influence of professionalism on the formation of professional character and its associated conducts is one of the challenges in medical education and formation of professional identity $(7,8)$. The present article addresses the importance of professionalism in the formation of a desirable professional identity in a doctor.

\section{Professional identity}

In their analysis of professional identity, Cardoso et al. argued that the number of publications on this issue has increased during 2002 and 2011 and that the majority of these publications were produced in 2011. These articles mostly focused on developing the stages of professional identity as described by Jebri $(9,10)$. A doctor's professional identity is how he perceives and conducts himself as a doctor (11) and as such is a complex structure that connects motivations and competencies to acceptable professional roles (12). An old theory describes professional identity as a set of fixed attributes or social roles (13). Contemporary constructivist theories regard the formation of professional identity as a dynamic phenomenon that is in consistent harmony with the social and communication domains surrounding it (14-16). 
The formation of professional identity is a developing, active, dynamic, and constructive process and an essential part of competence-based education (17), which involves the development of professional values, ethical principles, and wishes, and a revision of one's performance (self-reflection) with regards to one's personal identity $(18,19)$.

Holden et al. suggest that the formation of professional identity is a changing process through which knowledge, skills, and decent human values and behaviors are combined with a doctor's own personal identity and main values (20).

Students enter the field of medicine with an already-established identity and strive to obtain a doctor's identity. This professional identity develops in the course of the students' socialization and is a process by which the professional individual learns to act in harmony with the practices of a particular community or group by internalizing its values and norms. Students need to fully grasp the identity they acquire and later reflect these experiences in the clinical setting. Thus, the educational environment should support the development of a professional identity and be accountable for presenting this identity and take note of any hidden formal and informal curricula (21).

\section{Discussion}

The role of professionalism is essential in developing professional identity, which is a process through which an ordinary individual becomes a doctor, and it consists of the followings: professionalism, and the development of both a professional (psychosocial) and a cultural identity. Accordingly, the US and Canada have presented educational innovations targeting the development of professional identity. A common characteristic of these educational techniques is the development of professional competence as central to the techniques. These innovations support the development of professional identities and share a significant part of the efforts made to improve the quality of care and increase flexibility for being humane, relevant, and acting like a humane doctor. Medical education authorities, thus, seek the best measures needed to train good doctors with a double emphasis on scientific development and maturation of humanity. Professional identity is ultimately acquired through one's own personal identity. The main components of developing identity are rooted in the dimensions of professionalism and professional development (excellence in service provision, growing self-knowledge, and vigorous monitoring) (22).

Professionalism is expected from doctors, however, they are never taught, and the medical community and the rest of the society believe that medical professionalism is threatened by its failures. The movement of professionalism was developed a few decades ago in response to these threats, and with the evolvement of medical care, professionalism was also analyzed in medicine according to its existential origin and necessity; then, trainings and evaluation methods were developed for it (23). The Carnegie Foundation holds that the formation of professional identity is the same as development of professional values and should be the backbone of medicine. People enter medical schools with identities already developed in childhood and wish to join the clinical medicine community and successfully acquire the identity of a medical student and a clinician with a strong sense of belonging to their chosen specialty. Therefore, the aim is to build an identity that integrates personal and professional values in the clinical setting for the service-recipient community. Cruess believes that the real aim in teaching professionalism is to help students develop a desirable professional identity and this needs to become a principle of medical education. The next step after the realization of this goal is to track and evaluate the progress of every individual toward acquiring a professional identity. In the development of a desirable professional identity, it does not suffice to reach the DOES level (the conscious display of conducts expected of a doctor) in the Miller pyramid; rather, the IS level should be aimed by permanently showing attitudes, values, and conducts expected of a person for thinking, acting, and feeling like a doctor. According to the Miller pyramid, the KNOWS level indicates the bases of knowledge, including knowing and understanding the axial principles of professionalism. The SHOW HOW level indicates the behaviors that are expected of a doctor under supervision. In the DOES level, the individual consciously displays the conducts expected of a doctor. In the KNOWS HOW level, it is necessary to know when personal conduct is appropriate. Finally, at the pinnacle of the pyramid or the IS level, conducts should occur naturally, as the students are trained to think, act, and feel like a doctor and have a grasp over them; the graduated doctor repeatedly acts like a doctor according to the attitudes, values, and beliefs he has acquired over time; and as a result of the social experiences and interactions gathered in the clinical community, he displays his personal identity or identities (24-26).

The failure of the educational environment to support this model during the course of education can delay the process (27-29). Thus, students and residents are recommended to actively engage in the process of developing their own identities $(30,31)$. Frost-Regeh acknowledge that the aim is not to homogenize all personal identities into a standard; rather, maintaining the individual's personal identity and ensuring the diversity of identities are both important in the medical profession, and students are expected to realize the main virtues of a good doctor, including competence, kindness, honesty, and integrity, while retaining that 'self' with which they have first entered the medical school and to always regard these virtues as necessary components of a doctor's identity on which they will certainly insist in the future (32-33).

\section{Conclusion}

The results of previous studies suggest that the curriculum for the formation of a professional medical identity is still at its early stages of development and requires synergy between different perspectives to help develop a desirable professional identity among doctors. Very few studies have been conducted in the past decade on professionalism and professional medical identity. Yet, the majority acknowledge the existence of a reciprocal relationship between developing a desirable professional identity and establishing and strengthening professionalism. Moreover, modern medical 
education should be designed in such a way that leads to the development of a desirable professional identity, with professionalism acting as an essential part of its curricula throughout the entire course of a doctor's education, with the aim of acquiring a desirable professional identity.

\section{Conflict of Interests}

The authors declare that they have no competing interests.

\section{References}

1. Stern DT, ed. Measuring Medical Professionalism. New York, NY: Oxford University Press; 2006.

2. Saberi G, Nemati Sh, Fakhreiya S, Heidarzadeh A. Medical professionalism and its education to medical students. J Res Med Educ. 2013; 10(2):100-106.

3. Spector ND, Trimm RF. Teaching, Promoting and Assessing Professionalism Across the Continuum: A Medical Educator's Guide. The American Board of Pediatrics and the Association of Pediatric Program Directors. www.abp.org/ABPWebsite/publicat/professionalism.

4. MacKenzie CR. Professional and medicine. HSS J. 2007;3(2):222-227.

5. Kirk LM. Professionalism in medicine: definitions and considerations for teaching. Baylor Uni Med Center. 2007;20(1):13-16.

6. Wilson I, Cowin LS, Johnson M, Young H. Professional identity in medical students: Pedagogical challenges to medical education. Teach Learn Med. 2013;25:369-373.

7. Wagner P, Hendrich J, Moseley G, Hudson V. Defining medical professionalism: a qualitative study. Med Educ. 2007;41(3):288-94.

8. Cohen JJ. Professionalism in medical education, an American perspective: from evidence to accountability. Med Educ. 2006;40(7):607-17.

9. Jebril MY. The evolution and measurement of professional identity. PhD., Disseration. The Graduate School of the Texas Woman's University, College of Health Sciences 2008-11.

10. White MT, Borges NJ, Geiger S. Perceptions of factors contributing to professional identity development and specialty choice: a survey of third- and fourth-year medical students. Ann Behav Sci Med Educ. 2011;17(1):18-23.

11. Cole M, Walker S. Teaching and stress. Milton Keynes: open University Press. 1989.

12. Gleeson C. Education beyond competencies: a participative approach to professional development. Med Educ. 2010;44(4):404-411.

13. Cruess RL, Cruess SR, Boudreau JD, Snell L, Steinert Y. A schematic representation of the professional identity formation and socialization of medical students and residents: A guide for medical educators. Acad Med. 2015;90:718-725.

14. Talisman N, Harazduk N, Rush C, Graves K, Haramati A. The impact of mind-body medicine facilitation on affirming and enhancing professional identity in health care professions faculty. Acad Med. 2015:90:780-784.

15. Adler SR, Chang A, Loeser H, Cooke M, Wang J, Teherani A. The impact of intramural grants on educators' careers and on medical education innovation. Acad Med. 2015;90:827-831.

16. Pimentel MH, Pereira FA, Pereira MA The Constraction of social and professional identity of profession: NURSING. Prismasocial. 2011;7.

17. RamosIi FRS, Ramos Do Ó J. Bioethics and professional identity the healthcare worker's construction of the experience of him/herself. Inteface. 2009;13(29).

18. Korica M, Molloy E. Making sense of professional identities: Stories of medical professionals and new technologies. Human Relations. 2010; 63(12):1879-190

19. Holden MD, Buck E, Luk J, Ambriz F, Boisaubin EV, Clark MA, et al. Professional identity formation: Creating a longitudinal framework through TIME (transformation in medical education). Acad Med. 2015;90:761-767.

20. Mayer M, Newton D. Primary Care "Provider" and Professional Identity. JAMA. 2016;316(13):1411.

21. Wald HS. Professional Identity (Trans) Formation in Medical Education: Reflection, Relationship, Resilience. Acad Med. 2015;90(6):7016.

22. Levinson W, Ginsburg S, Hafferty FW, Lucey CR Understanding Medical Professionalism. New York, NY McGraw Hill. 2014.

23. Hafferty FWCruess RL, Cruess SR, Steinert Y. Professionalism and the socialization of medical students. Teaching Medical Professionalism. New York, NY Cambridge University Press. 2009:53-73.

24. Bebeau MJKenny N, Shelton W. Evidence based character development. Lost Virtue: Professional Character Development in Medical Education (Advances in Bioethics, Volume 10). Oxford, UK Elsevier. 2006:47-87.

25. Monrouxe LV. Identity, identification and medical education: Why should we care? Med Educ. 2010;44:40-49.

26. Jarvis-Selinger S, Pratt DD, Regehr G. Competency is not enough: Integrating identity formation into the medical education discourse. Acad Med. 2012;87:1185-1190.

27. Forsythe GB. Identity development in professional education. Acad Med. 2005; S112-S117.

28. MacLeod A. Caring, competence and professional identities in medical education. Adv Health Sci Educ Theory Pract. 2011;16:375-394.

29. Hafferty FWCruess RL, Cruess SR, Steinert Y. Professionalism and the socialization of medical students. Teaching Medical Professionalism. New York, NY Cambridge University Press. 2009:53-73.

30. Jarvis-Selinger S, Pratt DD, Regehr G. Competency is not enough: Integrating identity formation into the medical education discourse. Acad Med. 2012;87:1185-1190.

31. Cruess RL, Cruess SR, Boudreau JD, Snell L, Steinert Y. Reframing medical education to support professional identity formation. Acad Med. 2014;89:1446-1451.

32. Cruess RL, Cruess SR. Teaching medicine as a profession in the service of healing. Acad Med. 1997;72:941-952.

33. Shulman S. Signature pedagogies in the professions. Daedalus. 2005; 134:52-59. 